\title{
Planned Dose Frequency
}

National Cancer Institute

\section{Source}

National Cancer Institute. Planned Dose Frequency. NCI Thesaurus. Code C147513.

The intended number of times a substance is administered within a specific time period. 